\title{
Toward a Domain-Specific Approach to the Study of Parental Psychological Control: Distinguishing Between Dependency-Oriented and Achievement- Oriented Psychological Control
}

\author{
Bart Soenens, ${ }^{1}$ Maarten Vansteenkiste, ${ }^{1}$ and \\ Patrick Luyten ${ }^{2}$ \\ ${ }^{1}$ Ghent University \\ ${ }^{2}$ University of Leuven
}

\begin{abstract}
Theory and research suggest that psychologically controlling parenting can be driven by parental concerns in two different domains, that is, interpersonal closeness and achievement. Three studies addressing this hypothesis are presented. Study 1 provides evidence for the validity of the Dependency-Oriented and Achievement-Oriented Psychological Control Scale (DAPCS), a new measure assessing psychological control in these two domains. Study 2 showed that dependencyoriented and achievement-oriented psychological control were related in expected ways to parental separation anxiety and perfectionism in a sample of mothers and fathers. Finally, Study 3 showed that dependencyoriented and achievement-oriented psychological control were differentially related to middle adolescent dependency and self-criticism and that these personality features act as specific intervening variables between the domain-specific expressions of psychological control and depressive symptoms. It is argued that the distinction between two domain-specific expressions of psychological control may allow for a more intricate analysis of the processes involved in intrusive parenting.
\end{abstract}

Since the 1990s, developmental research has shown a strong interest in the construct of parental psychological control, a parenting dimension characteristic of parents who pressure their children to comply with their own agenda through insidious and manipulative

Correspondence concerning this article should be addressed to Bart Soenens, Department of Developmental, Social, and Personality Psychology, Henri Dunantlaan 2, B-9000 Ghent, Belgium. E-mail: Bart.Soenens@ugent.be.

Journal of Personality 78:1, February 2010

(C) 2010, Copyright the Authors

Journal compilation (C) 2010, Wiley Periodicals, Inc.

DOI: $10.1111 / \mathrm{j} .1467-6494.2009 .00614 . x$ 
tactics (Barber, 1996). Such tactics include guilt induction, shaming, and love withdrawal (i.e., making parental care contingent upon the child's compliance to parental demands; Barber \& Harmon, 2002). Although parents may not always be consciously aware of their own use of psychological control, psychologically controlling tactics coerce children into compliance by appealing to internally pressuring feelings in children's functioning, such as shame, guilt, pride, and separation anxiety (Barber, 1996; Grolnick, 2003). Parental psychological control has been shown to predict a variety of adjustment problems - and internalizing problems in particular - in children and adolescents. Cross-sectional and longitudinal studies have demonstrated positive associations between psychological control and depression (Barber, 1996; Barber, Stolz, \& Olsen, 2005), anxiety (Pettit \& Laird, 2002), and low self-esteem (Soenens, Vansteenkiste, Luyten, Duriez, \& Goossens, 2005). Research also demonstrates that parents' use of psychological control is multiply determined by a complex and reciprocally related set of factors, including social-contextual factors (e.g., marital conflict; Buehler, Benson, \& Gerard, 2006), adolescents' own adjustment (e.g., problem behavior; Pettit \& Laird, 2002), and parents' personality functioning (e.g., perfectionism; Soenens, Elliot, et al., 2005).

To date, most studies on psychological control have relied on general measures of psychological control (e.g., Barber's 1996 Psychological Control Scale-Youth Self-Report [PCS-YSR]) without specifying the issues that are involved in parents' use of psychological control. In this study, we propose and test the idea that the use of psychological control can revolve around at least two qualitatively different issues, that is, issues of relatedness and interpersonal closeness and issues of achievement and perfection. These two domains of psychological control closely parallel two fundamental developmental lines that have been distinguished in psychodynamic theories of personality development (Blatt, 2004), that is, interpersonal relatedness and self-definition. Accordingly, the goal of this study was to explore the validity of a distinction between two domain-specific expressions of psychological control, that is, dependency-oriented and achievement-oriented psychological control. Guided by Blatt's (1974, 2004) theory, we tested the idea that these two expressions of psychological control relate (a) to specific antecedents in parents' functioning and (b) to specific personality vulnerabilities to depressive symptoms in adolescents' functioning (i.e., dependency and self-criticism). 


\section{Blatt's Theory of Personality Development and Vulnerability for Depression}

The theory of Blatt (1974, 2004; Blatt \& Shichman, 1983) distinguishes between a dependent and a perfectionist/self-critical personality orientation based on people's preoccupation with one of two fundamental developmental lines: the "interpersonal relatedness" line, which involves the development of the capacity to establish increasingly mature and reciprocal relationships, and the "self-definition" line, which involves the development of a consolidated, realistic, and positive self-concept. Ideally, these two lines develop in a reciprocal interaction, thereby mutually reinforcing each other. However, excessive emphasis on one developmental line to the neglect of the other line, as expressed in excessive dependency or selfcriticism, respectively, would result in increased vulnerability for distress and psychopathology (Blatt \& Shichman, 1983).

Vulnerability associated with dependency is characterized by strong concerns involving interpersonal relations. Dependent individuals rely intensely on others to provide and maintain a sense of well-being, resulting in difficulties with separation and loss. Negative life events in the interpersonal domain (e.g., divorce) may lead to a type of depression characterized by feelings of loneliness and fears of abandonment (Blatt, 1974). Individuals with high levels of self-criticism or self-critical perfectionism mainly attempt to obtain approval and praise by meeting high performance standards, especially in the areas of school and work. Their high personal standards result in harsh self-scrutiny and a constant striving for excessive achievement and perfection. When faced with experiences of failure in achievement-related areas, these individuals may develop a type of depression characterized by feelings of inferiority, failure, and guilt (Blatt, 1974). An extensive body of research has documented theoretically expected relations between dependency and self-criticism and depression, coping strategies, and interpersonal functioning (for reviews, see Blatt, 2004; Zuroff, Mongrain, \& Santor, 2004). Blatt's theory implies a continuous view on normal and pathological personality development, implying that depression ranges along a continuum from dysphoria to clinical depression (Blatt, 2004). Given this continuous view, Blatt (2004) predicted similarity between factors that predispose individuals to transient dysphoric experiences and factors that create a vulnerability to a pervasive depressive disorder (Luyten, Blatt, Van Houdenhove, \& Corveleyn, 2006). 
Importantly, according to Blatt and colleagues (e.g., Blatt, 1974; Blatt \& Homann, 1992), dependent and self-critical individuals are characterized by a markedly different developmental history. Dependency develops in families where parents manipulate the attachment bond with the child and use their love and care to control the child. Specifically, love and acceptance are made contingent on the child's dependence on the parents. As a consequence, the child experiences insecurity about the parents' care, resulting in a dependent orientation characterized by fears about loss and by a clinging interpersonal style. Self-critical individuals typically experience their parents' love as contingent upon meeting very strict parental demands for achievement. These children are criticized and blamed for achieving less than perfectly. As children interiorize this parental criticism, they develop a self-critical orientation characterized by harsh self-evaluation (Blatt \& Homann, 1992). Despite their differential origins, dependency and self-criticism/perfectionism both render adolescents vulnerable to internalizing problems in general and to depression in particular (Blatt, 1974, 2004).

Despite the appealing nature of these formulations, there is a dearth of research addressing Blatt and Homann's (1992) predictions about relationships between family and parenting variables and dependency and self-criticism. In addition, with some important exceptions (e.g., McCranie \& Bass, 1984), much of this research has relied on general and rather undifferentiated assessments of parenting. This research has typically shown that, whereas general measures of controlling and pressuring parenting are positively related to self-criticism, such measures are less consistently related to dependency (Amitay, Mongrain, \& Fazaa, 2008; Koestner, Zuroff, \& Powers, 1991; Mongrain, 1998; Whiffen \& Sasseville, 1991). It is proposed here that a more differentiated assessment of parental psychological control in the domains of interpersonal closeness and achievement, respectively, may allow for a more fine-grained test of Blatt and Homann's (1992) developmental hypotheses.

\section{Toward a Domain-Specific Approach to the Study of Psychological Control}

In line with the two fundamental developmental lines distinguished by Blatt (1974, 2004), two different themes appear recurrently in 
accounts of the dynamics involved in psychologically controlling parenting, one theme relating to issues of relatedness, dependency, and separation anxiety and another theme involving issues of achievement, performance, and perfectionism.

Controlling parents in general and psychologically controlling parents in particular have been described as fostering separation anxiety (Wood, 2006), overprotective (Parker, 1983), and possessive (Barber \& Harmon, 2002). Common to these accounts is the idea that controlling parenting may result from parental intolerance of their children's increasing separation and independence (Hock, Eberly, Bartle-Haring, Ellwanger, \& Widaman, 2001). Parental control is then used as a means to make children emotionally and psychologically dependent on the parent. Driven by separation anxiety, parents restrict attempts by children to obtain some degree of independence because they consider such attempts as a threat to the bond between parent and child (Barber \& Harmon, 2002). In line with this, Soenens, Vansteenkiste, Duriez, and Goossens (2006) found that parental separation anxiety significantly predicted a general measure of parental psychological control.

Closely related to this description of controlling parents as dependency oriented is the notion of the enmeshed family (Green \& Werner, 1996; Manzi, Vignoles, Regalia, \& Scabini, 2006). Enmeshed families are characterized by a lack of interpersonal boundaries between their members, which hinders the development of children's healthy individuation. Children are not allowed to have their own lives and experiences. In such families, parents use control to keep family members within strictly defined family boundaries (Barber \& Buehler, 1996).

Apart from being dependency oriented, (psychologically) controlling parents have also been described as achievement oriented (Kenney-Benson \& Pomerantz, 2005), self-critical and perfectionist (Flett, Hewitt, MacDonald, \& Oliver, 2002), and high on fear failure (Elliot $\&$ Thrash, 2004). Achievement-oriented parents, as they pressure themselves to achieve high performance and as they perceive poor performance as a threat to their self-worth, are likely to behave in a controlling way toward their children (Grolnick, 2003). Much in the same way as they push themselves to achieve perfection in their performance, they demand perfection and high levels of achievement from their children (Flett et al., 2002). Psychological control is then used to communicate these demands for achievement. In line with 
this, Elliot and Thrash have shown that parental fear of failure, which involves a tendency to avoid mistakes in achievement contexts, is related to parental love withdrawal, one of the key components of psychological control. Further, Soenens, Elliot, et al. (2005) found that parental maladaptive perfectionism-defined as the extent to which parents are overly concerned with making mistakes - was positively related to Barber's (1996) general measure of psychological control. Finally, Grolnick and colleagues have shown in a series of experimental studies that mothers who received achievement-oriented instructions acted in a more controlling fashion toward their children (e.g., Grolnick, Price, Beiswenger, \& Sauck, 2007).

The notion that psychological control can be driven by achievement-related concerns is reminiscent of the construct of a perfectionist family climate. Frost, Marten, Lahart, and Rosenblate (1990) defined a perfectionist climate as typical of families where parents set exaggerated standards for achievement and where children anticipate parental criticism when standards are not met. Children from such families are likely to develop a constricted and performanceoriented approach to achievement situations (e.g., McArdle \& Duda, 2005).

The accounts and findings discussed in the preceding paragraphs suggest that it is useful to distinguish between (a) dependencyoriented psychological control (DPC), that is, the use of psychological control as a means to keep children within close physical and emotional boundaries, and (b) achievement-oriented psychological control (APC), that is, the use of psychological control to make children comply with parental standards for achievement. Although parents may not always be consciously aware of their use of these controlling behaviors, adolescents' perceptions of their parents as psychologically controlling may render adolescents vulnerable to depressive symptoms. Specifically, we hypothesize that children who perceive their parents as high on DPC are excessively preoccupied with issues of interpersonal closeness, thereby displaying a dependent orientation. Children who perceive their parents as high on APC are excessively preoccupied with issues of achievement and perfection and thus display a selfcritical orientation. Both dependency and self-criticism, in turn, predict independent variance in adolescents' depressive symptoms (Blatt, 2004). 


\section{The Present Studies}

The general purpose of this research program is to examine the validity of a distinction between DPC and APC and to examine whether these domain-specific expressions of psychological control relate differentially to features of parents' and adolescents' personality functioning. The main aim of Study 1 was to examine the validity of the distinction between DPC and APC in adolescent perceptions of their parents. Study 2 was designed to examine whether the distinction between DPC and APC can also be found in parents' own perception of their rearing style and whether different parental features (i.e., separation anxiety and maladaptive perfectionism) are differentially related to DPC and APC. In Study 3, we examined the hypothesized relationships between perceived DPC, APC, dependency, self-criticism, and depressive symptoms in a large sample of middle adolescents.

Throughout these studies, gender differences in DPC and APC were explored. According to Blatt (1974, 2004), cultural stereotypes place more emphasis on issues of relatedness and care for women and more emphasis on issues of self-definition and achievement for men. Developmental disruptions of these two developmental issues follow a similar gender-specific pattern such that a dependent orientation is more typical of females and a self-critical orientation is more typical of males (Blatt, 2004). Extrapolating these ideas to the distinction between DPC and APC, one may expect that mothers would score higher on DPC than fathers whereas fathers may score higher on APC than mothers. Continuing this reasoning, parents may also more often use DPC toward daughters and may more often use APC toward sons.

\section{STUDY 1}

Through exploratory and confirmatory factor analysis, Study 1 aims to examine the distinction between perceived parental DPC and APC. To assess the external validity of this distinction, both scales are related to well-established measures of parenting style dimensions and to measures of global family functioning. First, we examined relationships between the two domain-specific expressions of psychological control and three parenting dimensions, that is, general psychological control, autonomy support, and support (i.e., 
warmth and responsiveness). It is hypothesized that DPC and APC, as they both represent manifestations of an intrusive and autonomysuppressing parent-child relationship, are positively related to a general psychological control scale (Barber, 1996) and negatively to parental autonomy support (Grolnick, 2003). In contrast, we expected DPC and APC to be differentially related to a measure of parental support (responsiveness, warmth). The strong emphasis on achievement inherent in APC most likely impedes feelings of closeness and warmth in the parent-child relationship. In contrast, DPC is expected to be unrelated or even positively related to perceived parental support. As DPC entails parental behavior to keep the child within close proximity, DPC involves a strong emphasis on the parent-child bond. Children may thus perceive their parents as caring and concerned with their development. However, these high levels of connectedness with the parent come at the expense of the child's need for autonomy, because the child is forced to choose between reliance on the parent and exploration of the broader social world. Thus, it is expected that correlations between DPC and parental support are less pronounced than correlations between APC and support. Second, in addition to these parenting variables, which represent qualities of the parent-child dyad, we also examined associations with two family-level constructs, that is, family enmeshment and a perfectionist family climate. It is expected that, whereas DPC would be particularly strongly related to ratings of an enmeshed family climate, APC would be specifically related to a perfectionist family climate.

\section{Method}

\section{Participants and Procedure}

Participants were first-year undergraduate students at a Belgian university. Because this study focused on late adolescents, participants older than 25 years were not included. The final sample $(N=348)$ ranged in age from 17 to 25 with a mean age of 18.37 years $(S D=0.89)$ and was $79 \%$ female. All participants were Dutch-speaking and of Belgian nationality. Of the participants, $76 \%$ came from intact, two-parent families, $18 \%$ had divorced parents, and $6 \%$ of the adolescents came from a family in which one of the parents had deceased. The study took place in the context of collective testing sessions that are organized at the department of psychology. Participation in the study was voluntary, and participants 
received course credit for attending the sessions. None of the students refused participation, and anonymity was guaranteed.

\section{Measurements}

Dependency-oriented psychological control and achievement-oriented psychological control. The Dependency-oriented and Achievement-oriented Psychological Control Scale (DAPCS) was developed to assess adolescents' perceptions of parental DPC and APC. On the basis of Blatt's (2004) and Barber's (1996) theorizing, DPC was defined as the use of psychological control in the domain of parent-child closeness, where control is used as a means to keep children within close physical and emotional boundaries. APC was defined as the use of psychological control in the domain of achievement, where psychological control is used as a means to make children comply with excessive parental standards for performance. On the basis of these operational definitions, 10 items were formulated for each scale using a committee approach. The three authors of this paper, each of whom is familiar with the literatures on both parenting and Blatt's theory, wrote items and discussed these items until consensus was reached. This phase of item generation was followed by a pilot study and a phase of consultation with experts in the field. After rewriting some of the items, we arrived at the set of items displayed in Table 1. The formulation of these items was guided by two important principles. First, parental conditional regard was posited as a common theme in all items. Conditional regard (sometimes also referred to as "love withdrawal") is indeed considered a core strategy of psychologically controlling parenting in classic (e.g., Schaefer, 1965) and more recent accounts of psychological control (e.g., Barber \& Harmon, 2002). Through the use of pressuring tactics such as shaming, guilt induction, and appeals to pride, psychologically controlling parents convey the message to their children that parental love depends on the child being or behaving as the parent wishes. Second, we incorporated a recently introduced distinction between negative and positive conditional regard (Roth, Assor, Niemiec, Ryan, \& Deci, 2009) into the items. Whereas negative conditional regard involves the expression of negative feelings (e.g., guilt and disappointment) when the child does not behave as the parent demands, positive conditional regard involves the expression of positive feelings (e.g., pride and affection) when the child does act as the parent demands. To ensure that the findings obtained in this study are not uniquely due to either negative or positive conditional regard, the new scales contained items tapping both types of conditional regard. An example of an item tapping negative conditional regard reads " $\mathrm{My}$ mother is less friendly with me if I perform less than perfectly." An example of an item tapping positive 
Table 1

Factor Loadings of the PCA Following Oblique Rotation (PROMAX)

(Study 1)

\begin{tabular}{|c|c|c|c|c|}
\hline \multirow{2}{*}{$\begin{array}{l}\text { Items } \\
\text { My mother/My father... }\end{array}$} & \multicolumn{2}{|c|}{$\begin{array}{l}\text { Maternal } \\
\text { Ratings }\end{array}$} & \multicolumn{2}{|c|}{$\begin{array}{l}\text { Paternal } \\
\text { Ratings }\end{array}$} \\
\hline & DPC & APC & DPC & APC \\
\hline $\begin{array}{l}\text { 1. shows that } \mathrm{s} / \mathrm{he} \text { is disappointed with me } \\
\text { if I do not rely on her/him for a problem }\end{array}$ & .94 & -.33 & .77 & -.23 \\
\hline $\begin{array}{l}\text { 2. blames me that I no longer want to do } \\
\text { things that we used to enjoy }\end{array}$ & .74 & -.14 & .67 & .07 \\
\hline $\begin{array}{l}\text { 3. will make me feel guilty when I will } \\
\text { leave home permanently }\end{array}$ & .50 & .32 & .46 & .35 \\
\hline $\begin{array}{l}\text { 4. shows that } \mathrm{s} / \text { he is disappointed in me if } \\
\text { I do not want to share certain things } \\
\text { with } \mathrm{him} / \text { her }\end{array}$ & .76 & -.04 & .86 & -.16 \\
\hline $\begin{array}{l}\text { 5. makes me feel guilty if my ideas differ } \\
\text { from hers/his }\end{array}$ & .46 & .40 & .43 & .38 \\
\hline $\begin{array}{l}\text { 6. is only happy with me if I rely } \\
\text { exclusively on her/him for advice }\end{array}$ & .67 & .14 & .61 & .15 \\
\hline $\begin{array}{l}\text { 7. only shows her/his love for me as long } \\
\text { as we keep doing everything together }\end{array}$ & .64 & .14 & .70 & -.06 \\
\hline $\begin{array}{l}\text { 8. interferes in my problems, even if I } \\
\text { prefer to solve them myself }\end{array}$ & .55 & .16 & .54 & .14 \\
\hline $\begin{array}{l}\text { 9. is only friendly with me if I rely on her/ } \\
\text { him instead of on my friends }\end{array}$ & .70 & .07 & .64 & .03 \\
\hline $\begin{array}{l}\text { 10. is only happy with me if I look at things } \\
\text { her/his way }\end{array}$ & .40 & .49 & .25 & .57 \\
\hline $\begin{array}{l}\text { 11. is less friendly with me if I perform less } \\
\text { than perfectly }\end{array}$ & .12 & .67 & .03 & .74 \\
\hline $\begin{array}{l}\text { 12. shows that } \mathbf{s} / \text { he is disappointed in me if } \mathbf{I} \\
\text { make a mistake }\end{array}$ & .26 & .31 & .12 & .46 \\
\hline $\begin{array}{l}\text { 13. is less attentive to me if I do not } \\
\text { perform up to my fullest potential }\end{array}$ & -.01 & .83 & .06 & .78 \\
\hline $\begin{array}{l}\text { 14. shows that } \mathrm{s} / \text { he loves me less if I } \\
\text { perform badly }\end{array}$ & -.08 & .94 & .00 & .87 \\
\hline $\begin{array}{l}\text { 15. makes me feel guilty if my performance } \\
\text { is inferior }\end{array}$ & .03 & .70 & -.02 & .77 \\
\hline $\begin{array}{l}\text { 16. only shows her/his love for me if I get } \\
\text { good grades }\end{array}$ & -.06 & .90 & -.16 & .89 \\
\hline
\end{tabular}


Table 1 (Cont.)

\begin{tabular}{lrrrrr}
\hline Items & $\begin{array}{c}\text { Maternal } \\
\text { Ratings }\end{array}$ & \multicolumn{2}{c}{$\begin{array}{c}\text { Paternal } \\
\text { Ratings }\end{array}$} \\
\hline My mother/My father $\ldots$ & DPC & APC & DPC & APC \\
\hline $\begin{array}{l}\text { 17. only respects me if I am the best at } \\
\text { everything }\end{array}$ & -.08 & .87 & -.14 & .86 \\
$\begin{array}{l}\text { 18. is only friendly with me if I excel in } \\
\text { everything I do }\end{array}$ & -.04 & .89 & -.02 & .60 \\
$\begin{array}{l}\text { 19. appreciates me more if I pursue high } \\
\text { standards }\end{array}$ & .03 & .72 & .04 & .64 \\
$\begin{array}{l}\text { 20. is only proud of me if I perform well on } \\
\text { exams }\end{array}$ & -.09 & .92 & -.09 & .83 \\
\hline
\end{tabular}

Note. Items in bold were not retained in the final scale scores. DPC $=$ dependencyoriented psychological control; APC $=$ achievement-oriented psychological control.

conditional regard reads "My mother is only proud of me if I excel in everything I do." Items were rated on 5-point Likert scales, ranging from 1 (strongly disagree) to 5 (strongly agree). Mean scores on the 10 DPC items ranged between 1.69 and 2.59 and between 1.50 and 2.28 in the maternal and paternal ratings, respectively. Mean scores on the 10 APC items ranged between 1.55 and 2.82 and between 1.54 and 3.03 in the maternal and paternal ratings, respectively. Although these means are low, they are in line with previous research on psychological control (e.g., Barber, 1996). Moreover, scores on each of item varied between 1 and 5, indicating that participants made use of the full range of scores. As a consequence, there was quite a lot of variability in the item scores, as underscored by the finding that the standard deviation of each individual item score was well above 0.50 . Further information about the psychometrics of this new measure is provided in the Results section.

Other parenting style dimensions. Three parenting style dimensions were assessed to externally validate the distinction between DPC and APC, namely, psychological control, autonomy support, and support. Participants rated these scales for mothers and fathers separately. Psychological control was assessed with the eight-item PCS-YSR (Barber, 1996). A sample item reads: "My mother/father is always trying to change how I feel or think about things." Cronbach's $\alpha$ was .89 for both maternal and paternal ratings. Autonomy support was tapped with six items drawn from the Autonomy Support scale of the Perceptions of Parents Scale (Grolnick, Ryan, \& Deci, 1991; e.g., "My mother, whenever possible, allows 
me to choose what to do"). Cronbach's $\alpha$ was .86 for maternal ratings and .88 for paternal ratings. Support was tapped with seven items from the Children's Report on Parent Behavior Inventory (CRPBI; Schaefer, 1965). A sample item reads "My father/mother makes me feel better after I discussed my worries with him/her." Cronbach's $\alpha$ was .94 for maternal ratings and .92 for paternal ratings.

Perfectionist and enmeshed family climate. As a measure of the extent to which adolescents perceive their family climate as perfectionist and highly demanding, we used two scales from the Frost Multidimensional Perfectionism Scale (MPS; Frost et al., 1990), that is, Parental Expectations (five items; e.g., "Only outstanding performance is good enough in my family") and Parental Criticism (four items; e.g., "My parents never tried to understand my mistakes"). As previous research (e.g., Stumpf \& Parker, 2000) has shown that the items of these two scales load onto a single factor, a perfectionist family climate score was created by computing the mean of the items of both scales. Cronbach's $\alpha$ was .90. As a measure of enmeshment, participants completed the seven-item enmeshment subscale of the Colorado Self-Report of Family Functioning Inventory (Bloom, 1985; Manzi et al., 2006; e.g., "Family members find it hard to get away from each other"). Cronbach's $\alpha$ was .76.

\section{Results}

\section{Internal Structure and Reliability of the DAPCS}

Following recommendations for good practice in scale development (e.g., Henson \& Roberts, 2006), the internal structure of our new instrument was examined with a combination of exploratory and confirmatory factor analyses. A principal components analysis (PCA) was performed on maternal and paternal ratings of the items separately. PCA on the 20 maternal items yielded two components with an eigenvalue larger than 1 (9.66 and 2.10), explaining $48 \%$ and $10 \%$ of the variance, respectively. Moreover, the scree plot indicated that the first two components accounted for the largest proportion of explained variance. PCA on the 20 paternal items yielded three components with an eigenvalue larger than 1 (8.21, 2.20 , and 1.17 ), explaining $41 \%, 11 \%$, and $6 \%$ of the variance, respectively. However, as the scree plot showed a clear elbow after the first two components, two components were extracted for both the maternal and paternal ratings. An oblique rotation (PROMAX) was 
performed because it was anticipated that DPC and APC would be substantially correlated. Table 1 displays the item loadings.

As shown in Table 1, nine DPC items had substantial loadings $(>.40)$ on the first component in both the maternal and the paternal solutions. One DPC item did not load on its intended component in the paternal solution and was removed from the scale. One of the remaining nine items had a substantial cross-loading $(>.40)$ in the maternal solution and was also removed from the scale. Removal of these two items resulted in an eight-item DPC scale. Cronbach's $\alpha$ was .86 for the maternal ratings and .83 for the paternal ratings. Nine APC items (out of 10) had substantial loadings on the second component in both the maternal and paternal solutions. Removal of one APC item that did not load on its intended factor resulted in a nine-item APC scale. Cronbach's $\alpha$ was .93 for the maternal ratings and .91 for the paternal ratings. Maternal ratings of DPC and APC were positively correlated, $r=.61, p<.001$, and so were paternal ratings of DPC and APC, $r=.52, p<.001$. Maternal and paternal ratings of DPC were positively correlated, $r=.43, p<.001$, and so were maternal and paternal ratings of APC, $r=.49, p<.001$.

Next, we performed a confirmatory factor analysis (CFA) on the 17 selected items ( 8 for DPC and 9 for APC) to further validate the distinction between DPC and APC. CFA was conducted using Lisrel 8.50 with maximum likelihood estimation (Jöreskog \& Sörbom, 1996). To evaluate the goodness of fit of the factor structure, the standardized root mean square residual (SRMR) and the root mean squared error of approximation (RMSEA) were selected. According to $\mathrm{Hu}$ and Bentler (1999), the combined cutoff values of .09 for SRMR and .06 for RMSEA indicate a good model fit. In addition, we also inspected the comparative fit index (CFI) with values of .95 or above indicating good fit. To compare models, $\chi^{2}$ difference tests were used. Two models were compared, that is, a one-factor model, assuming that the associations among the items are explained by a single underlying "psychological control" factor, and a two-factor model assuming a distinction between DPC and APC. No crossloadings or correlated errors between items were allowed. The two-factor solution, $\chi^{2}(118)=260.93$, RMSEA $=.06, \mathrm{SRMR}=.06$, $\mathrm{CFI}=.99$, for maternal ratings and $\chi^{2}(118)=262.86$, $\mathrm{RMSEA}=$ $.06, \mathrm{SRMR}=.06, \mathrm{CFI}=.98$, for paternal ratings, was clearly favored over the one-factor solution, $\chi^{2}(119)=846.39, \operatorname{RMSEA}=.13$, $\mathrm{SRMR}=.10, \mathrm{CFI}=.92$, for maternal ratings and $\chi^{2}(119)=724.26$, 
RMSEA $=.12$, SRMR $=.10, \mathrm{CFI}=.91$, for paternal ratings, as indicated by a significantly different chi-square statistic, $\Delta \chi^{2}=585.46$, $d f=1, p<.001$, for maternal ratings and $\Delta \chi^{2}=461.40, d f=1$, $p<.001$, for paternal ratings. Standardized loadings in the maternal solution ranged from .57 to .90 (all $p s<.001$ ) with a mean of .74 , and loadings in the paternal solution ranged from .53 to .87 (all $p s<.001$ ) with a mean of .68. On the basis of the CFA results, we also computed the reliability estimate proposed by Leone, Perugini, Bagozzi, Pierro, and Mannetti (2001). This estimate is similar to Cronbach's $\alpha$, but it relaxes the assumption that each indicator is weighted equally in determining the composite score. Instead, it takes into account the size of the standardized factor loadings in the CFA solution. Estimates for maternal DPC and APC were .87 and .93, respectively. Estimates for paternal DPC and APC were .84 and .91, respectively.

\section{Gender Differences}

To examine the effects of parent and adolescent gender on DPC and APC, we performed a repeated measures multivariate analysis of variance (MANOVA) with parent gender as a within-subjects variable and adolescent gender as a between-subjects variable. A significant multivariate effect was obtained for parental gender, Wilks $\lambda=0.84$, $F(2,330)=32.09, p<.001, \eta^{2}=.16$, and for adolescent gender, Wilks $\lambda=0.96, F(2,330)=7.62, p<.01, \eta^{2}=.04$. The interaction between parent and adolescent gender was not significant, Wilks $\lambda=0.99$, $F(2,330)=1.02, p>.05, \eta^{2}=.01$. Univariate follow-up analyses indicated effects of parental gender on DPC, $F(1,331)=22.91, p<.001$, $\eta^{2}=.07$, and APC, $F(1,331)=16.41, p<.001, \eta^{2}=.05$. Whereas mothers were rated as higher on DPC $(M=2.12, S D=0.77)$ compared to fathers $(M=1.86, S D=0.66)$, fathers were rated as higher on APC $(M=1.91, S D=0.81)$ compared to mothers $(M=1.68$, $S D=0.76)$. Adolescent gender had an effect on APC, $F(1,331)=6.41, p=.01, \eta^{2}=.02$, with males reporting higher APC $(M=1.97, S D=0.74)$ than females $(M=1.74, S D=0.79)$.

\section{Convergent and Discriminant Validity}

Correlations between the two domain-specific expressions of psychological control and other family and parenting variables are 


\section{Table 2}

Correlations and Partial Correlations of DPC and APC With Family and Parenting Variables (Study 1)

\begin{tabular}{|c|c|c|c|c|}
\hline & \multicolumn{2}{|c|}{$\mathrm{DPC}$} & \multicolumn{2}{|c|}{ APC } \\
\hline & $r$ & Partial $r$ & $r$ & Partial $r$ \\
\hline \multicolumn{5}{|l|}{ Maternal ratings } \\
\hline General psychological control & $.60 * * *$ & $.30 * *$ & $.71^{* *}$ & $.55 * *$ \\
\hline Autonomy support & $-.49 * * *$ & $-.27 * *$ & $-.53 * *$ & $-.34 * *$ \\
\hline Support & $-.23 * *$ & .07 & $-.47^{* * *}$ & $-.44 * *$ \\
\hline Enmeshed family climate & $.40 * *$ & $.31 * *$ & $.27 * *$ & .04 \\
\hline Perfectionist family climate & $.46^{* * *}$ & .12 & $.65^{* *}$ & $.54 * *$ \\
\hline \multicolumn{5}{|l|}{ Paternal ratings } \\
\hline General psychological control & $.55^{* * *}$ & $.34 * *$ & $.66^{* * *}$ & $.52 * *$ \\
\hline Autonomy support & $-.43^{* * *}$ & $-.21^{* *}$ & $-.54 * *$ & $-.42 * *$ \\
\hline Support & -.10 & $.22 * *$ & $-.50 * *$ & $-.53 * *$ \\
\hline Enmeshed family climate & $.30 * * *$ & $.28^{* *}$ & $.14^{*}$ & -.02 \\
\hline Perfectionist family climate & $.42^{* * *}$ & .13 & $.64^{* * *}$ & $.54 * *$ \\
\hline
\end{tabular}

Note. DPC $=$ dependency-oriented psychological control; $\mathrm{APC}=$ achievement-oriented psychological control.

$* p<.01 . * * p<.001$.

presented in Table 2. Due to the relatively high sample size, our analyses attained high power. To avoid having small correlations flagged as significant, only correlations at $p<.01$ were considered significant. Because DPC and APC are substantially correlated, partial correlations were computed for DPC controlling for APC and vice versa. These partial correlations allow for an examination of the associations of each domain of psychological control with the validation measures, net of the effect of the domain of psychological control that is being controlled for. Thus, partial correlations that reach significance represent unique ("pure") associations of the domains of psychological control with the validation measures.

In both the maternal and the paternal ratings, DPC and APC were positively correlated with the general psychological control scale (PCS-YSR) and negatively with autonomy support. When controlling for the variance shared between DPC and APC, both still showed significant positive correlations with psychological control and significant negative correlations with autonomy support. 
DPC and APC were negatively related to parental support in the raw correlations. When we controlled for their shared variance, however, only APC was significantly negatively related to parental support. When we controlled for APC, DPC was unrelated to support in the maternal ratings and positively related to support in the paternal ratings. Thus, as expected, APC shows a more consistent negative association with parental support compared to DPC. The positive partial correlation between paternal DPC and support even indicates that, after removing the variance shared with APC, fathers who are perceived as high on DPC are, on average, perceived as supportive.

Finally, although DPC and APC were both positively related to perceptions of the family as enmeshed and perfectionist, the partial correlations showed a differentiated and expected pattern of associations. DPC was uniquely related to enmeshment and APC was uniquely related to a perfectionist family climate. Together with the differential relations with parental support, these findings support the divergent validity of the DPC and APC scales.

\section{STUDY 2}

The results of Study 1 provide preliminary evidence that DPC and APC represent distinct domain-specific expressions of psychological control in late adolescents' perceptions of their parents. The first question addressed in Study 2 is whether this distinction can be generalized to parents' own perception of their rearing style. Second, to further validate the distinction between DPC and APC, we examined whether different parental personality features would relate differentially to DPC and APC. Among other determinants (including socialcontextual pressures and child adjustment), parental personality has been shown to be significantly related to psychological control. For instance, Soenens et al. (2006) have shown that parental separation anxiety and maladaptive perfectionism are independently related to a general measure of psychological control. This study builds on those findings by examining whether separation anxiety and maladaptive perfectionism are each specifically and uniquely related to DPC and APC, respectively. In examining these hypothesized associations, we controlled for parental distress as a possible confounding variable because a number of studies have shown that parental proneness to 
depressive symptoms is positively related to parental use of psychological control (e.g., Schluterman, 2007).

\section{Method}

\section{Participants and Procedure}

Data for this study were collected by undergraduate students $(N=161)$ participating in a course on developmental psychology. Students were asked to administer questionnaires to the parents from two intact families, one family where parents would report on the relationship with their daughter and one where parents would report on the relationship with their son. It was required that participants would be the parents of an adolescent aged between 12 and 18 years. Parents were informed about the topic of the study (i.e., "parent-child relationships") and it was explained to them that participation to the study was voluntary and that they could discontinue participation at any time. Less than $2 \%$ of the parents who were invited refused to participate. Students scheduled a meeting with parents who agreed to participate and administered the questionnaires during a home visit. This procedure resulted in a sample of 322 fathers and mothers. Due to the sampling procedure, about half of the parents $(51 \%)$ reported on their parenting style in relation to a female child. The age of the adolescent child that parents reported on ranged between 13 and 18 years with a mean age of $16(S D=0.96)$. Mothers' mean age was 45 years $(S D=3.21)$. On a 6-point scale, mothers' mean educational level was $3.88(S D=1.17)$, indicating an average of 15 years of education. Fathers' mean age was 47 years $(S D=3.75)$. Fathers' mean educational level was $4.02(S D=1.39)$, also indicating about 15 years of education.

\section{Measures}

$D P C$ and $A P C$. Parents were administered a parent-report version of the DAPCS, including the eight-item DPC scale and the nine-item APC scale constructed in Study 1. For the purpose of this study, items were made amenable to parent self-report. For instance, the item "My mother/ father is less friendly with me if I perform less than perfectly" was changed into "I am less friendly with my son/daughter if $\mathrm{s} / \mathrm{he}$ performs less then perfectly." Cronbach's $\alpha$ of the DPC scale was .79 and .83 for mothers and fathers, respectively. Cronbach's $\alpha$ of the APC scale was .80 and .86 for mothers and fathers, respectively.

Separation anxiety. Parents rated 10 items of the Anxiety about Adolescent Distancing scale from the Parents of Adolescents Separation 
Anxiety scale (PASAS; Hock et al., 2001) that were selected on the basis of data from an independent sample of 540 mothers and 473 fathers (Soenens et al., 2006). The 10 items with the highest factor loadings in both the maternal and paternal data were selected for use in this study. This shortened scale was highly correlated with the original 21-item scale $(r=.95$ for both mothers and fathers). An example item reads "I dread thinking about what my life will be like after my teenager leaves home permanently." In this study, Cronbach's $\alpha$ was .85 for both mothers and fathers.

Maladaptive perfectionism. Parents completed two scales from the MPS (Frost et al., 1990), namely, Concern over Mistakes (nine items; e.g., "People will probably think less of me if I make a mistake") and Doubts about Actions (four items; e.g., "Even when I do something very carefully, I often feel that it is not quite right"). Past research has identified both scales as indicators of maladaptive perfectionism (Frost et al., 1990). A maladaptive perfectionism scale was constructed by computing the mean of the items tapping Concern over Mistakes and Doubts about Actions (see, e.g., Soenens, Vansteenkiste, et al., 2005). Cronbach's $\alpha$ was .90 and .88 for mothers and fathers, respectively.

Depressive symptoms. Depressive symptoms were measured using the Center for Epidemiologic Studies-Depression scale (CES-D; Radloff, 1977). A brief 12-item version was developed and validated by Roberts and Sobhan (1992). Parents indicated how often they had experienced symptoms of depression during the past week on a scale from from 0 (rarely or none of the time [less than one day]), to 1 (a couple of times [1-2 days]), to 2 (sometimes or regularly [3-4 days]), to 3 (most or all of the time [5-7 days]). An example item reads: "During the past week, I felt sad." Cronbach's $\alpha$ was .82 and .77 for mothers and fathers, respectively.

\section{Results}

\section{Confirmatory Factor Analysis}

We used CFA to examine the factor structure of the DAPCS in parents' perceptions. It was found that a two-factor solution, $\chi^{2}(118)=371.51, \mathrm{RMSEA}=.08, \mathrm{SRMR}=.07, \mathrm{CFI}=.93$, for maternal reports and $\chi^{2}(118)=412.95, \mathrm{RMSEA}=.09, \mathrm{SRMR}=.06$, $\mathrm{CFI}=.95$, for paternal ratings, fit the data better than a one-factor solution, $\chi^{2}(119)=653.63, \mathrm{RMSEA}=.12, \mathrm{SRMR}=.10, \mathrm{CFI}=.85$, for maternal ratings and $\chi^{2}(119)=662.78, \quad \operatorname{RMSEA}=.12$, $\mathrm{SRMR}=.09, \mathrm{CFI}=.90$, for paternal ratings, as evidenced by a 
significant difference in chi-square, $\Delta \chi^{2}=33.37, d f=1, p<.001$, for maternal reports and $\Delta \chi^{2}=28.87, d f=1, p<.001$, for paternal reports. Standardized factor loadings in the maternal solution ranged from .39 to .76 (all $p s<.001$ ) with a mean of .59 , and loadings in the paternal solution ranged from .46 to .76 (all $p$ s $<.001$ ) with a mean of .64. Reliability estimates according to Leone et al.'s (2001) formula were .81 and .83 for maternal DPC and APC, respectively. Reliability estimates for paternal DPC and APC were .84 and .87 , respectively.

\section{Descriptive Statistics}

Descriptive statistics for all the variables in this study are provided in Table 3. Prior to examining the hypothesized relationships between DPC, APC, separation anxiety, and maladaptive perfectionism, we explored the effects of a number of relevant background characteristics (i.e., gender, parent age, and parent educational level). First, to examine gender differences, we performed a repeated measures MANOVA with parent gender as a within-subjects variable, with adolescent gender as a between-subjects variable and with all study variables as dependent variables. A significant multivariate effect was obtained for parental gender, Wilks $\lambda=0.82, F(5,314)=14.41$, $p<.001, \eta^{2}=.18$, and for adolescent gender, Wilks $\lambda=0.96, F(5$, $314)=2.77, p<.05, \eta^{2}=.04$. The interaction between parent and adolescent gender was not significant, Wilks $\lambda=0.99, \quad F(5$, $314)=0.52, p>.05, \eta^{2}=.01$. Univariate follow-up analyses indicated effects of parental gender on APC, $F(1,317)=39.96, p<.001$, $\eta^{2}=.11$, and separation anxiety, $F(1,317)=14.66, \quad p<.001$, $\eta^{2}=.04$. Whereas fathers scored higher on APC $(M=1.76$, $S D=0.61)$ compared to mothers $(M=1.53, S D=0.48)$, mothers scored higher on separation anxiety $(M=2.48, S D=0.76)$ compared to fathers $(M=2.29, S D=0.70)$. Adolescent gender had an effect on APC, $F(1,318)=6.29, p=.01, \eta^{2}=.02$, with parents reporting higher APC toward their sons $(M=1.71, S D=0.61)$ than toward their daughters $(M=1.59, S D=0.61)$.

To examine the effects of parental age and educational level, correlations were computed between these background variables and the study variables. Parental age was unrelated to the study variables (all $p \mathrm{~s}>.05$ ). Maternal educational level was positively related to APC $(r=.16, p<.01)$ and negatively related to depressive symptoms $(r=-.13, p=.01)$ and separation anxiety $(r=-.19, p<.01)$. 
Paternal educational level was negatively related to DPC $(r=-.14$, $p=.01)$, depressive symptoms $(r=-.16, p<.01)$, and separation anxiety $(r=-.20, p<.001)$. Given that gender and educational level were related to the study variables, we controlled for the effects of these background variables in the primary analyses.

\section{Correlations and Regression Analyses}

Correlations between the study variables are provided in Table 3 . Both in the maternal and in the paternal data, separation anxiety and maladaptive perfectionism were both positively related to DPC and APC. The most pronounced correlations were obtained, however, for those associations that were theoretically anticipated (i.e., the association between separation anxiety and DPC and the correlation between maladaptive perfectionism and APC). In addition, parental depressive symptoms were significantly related to DPC and APC.

To examine unique associations between separation anxiety, maladaptive perfectionism, and the domain-specific expressions of psychological control, regression analyses were performed (Table 4). To control for the variance shared by DPC and APC, in a first step each scale was regressed on the other scale. For clarity of presentation, the

\section{Table 3}

Descriptive Statistics and Correlations Between Study Variables (Study 2)

\begin{tabular}{lccccc}
\hline Variable & 1 & 2 & 3 & 4 & 5 \\
\hline$M$ & 1.71 & 1.75 & 2.25 & 1.96 & 0.47 \\
$S D$ & 0.53 & 0.58 & 0.67 & 0.61 & 0.36 \\
1. DPC & - & $.60^{* * *}$ & $.66^{* * *}$ & $.46^{* * *}$ & $.35^{* * *}$ \\
2. APC & $.43^{* *}$ & - & $.33^{* *}$ & $.60^{* * *}$ & $.31^{* *}$ \\
3. Separation anxiety & $.57^{* *}$ & $.21^{* *}$ & - & $.39^{* * *}$ & $.32^{* * *}$ \\
4. Maladaptive perfectionism & $.39^{* *}$ & $.48^{* * *}$ & $.34^{* * *}$ & - & $.37^{* * *}$ \\
5. Depressive symptoms & $.30^{* *}$ & $.24^{* *}$ & $.35^{* * *}$ & $.40^{* * *}$ & - \\
$M$ & 1.67 & 1.53 & 2.45 & 1.94 & 0.52 \\
$S D$ & 0.49 & 0.48 & 0.74 & 0.65 & 0.41 \\
\hline
\end{tabular}

Note. Lower diagonal: descriptive statistics and correlation matrix of the maternal data; upper diagonal: descriptive statistics and correlation matrix of the paternal data. $\quad$ DPC $=$ separation-anxious psychological control, $\quad$ APC $=$ achievementoriented psychological control.

$* * p<.001$. 
Table 4

Regression Analyses Predicting DPC and APC (Study 2)

\begin{tabular}{lccccc}
\hline & \multicolumn{3}{c}{ Dependent Variable } \\
\cline { 2 - 3 } & \multicolumn{2}{c}{ Maternal Model } & & \multicolumn{2}{c}{ Paternal Model } \\
\cline { 2 - 3 } \cline { 5 - 6 } Predictor & DPC & APC & DPC & APC \\
\hline Adolescent gender & .02 & $-.15^{*}$ & & -.02 & -.02 \\
Parent level of education & -.09 & $.17^{*}$ & -.06 & $.12^{*}$ \\
Depressive symptoms & .02 & .05 & & .08 & .03 \\
Maladaptive perfectionism & .05 & $.30^{* *}$ & -.02 & $.38^{* * *}$ \\
Separation anxiety & $.46^{* * *}$ & -.07 & & $.50 * *$ & $-.18^{*}$ \\
$R^{2}$ & .40 & .31 & & .58 & .47 \\
\hline
\end{tabular}

Note. $\quad$ DPC $=$ dependency-oriented psychological control, $\mathrm{APC}=$ achievementoriented psychological control.

$* p<.01 . * * p<.001$.

results of this first step are not shown in Table 4. We controlled for the effects of adolescent gender, parental educational level, and parental depressive symptoms by entering these variables in the second step of the equation. In the third and final step, separation anxiety and maladaptive perfectionism were entered as simultaneous predictors of DPC and APC. Analyses were performed separately for maternal and paternal data. The results of the second and third steps are shown in Table 4. Parental separation anxiety was found to be uniquely related to DPC and parental maladaptive perfectionism was found to be uniquely related to APC, even when controlling for the background variables (Table 4). Note that the initial associations between depressive symptoms and the types of psychological control observed in the raw correlations (Table 3 ) were reduced to nonsignificance after we entered separation anxiety and maladaptive perfectionism as predictors of DPC and APC.

In sum, results from Study 2 show that the distinction between DPC and APC can be generalized to parents' own perceptions of their rearing behavior. Further, DPC and APC were each uniquely related to their hypothesized parental antecedents (i.e., separation anxiety and maladaptive perfectionism, respectively), a finding that further testifies to the validity of the distinction between DPC and APC. 


\section{STUDY 3}

Study 3 first aims to replicate the factorial distinctiveness of DPC and APC in a sample of middle adolescents. The main aim of Study 3 was to examine associations between the two domains of psychological control and adolescent dependency, self-criticism, and depressive symptoms. Specifically, we expected that DPC would be uniquely related to dependency whereas APC would be uniquely related to self-criticism in adolescents. Dependency and self-criticism would, in turn, explain independent variance in adolescent depressive symptoms, thus differentially mediating the effects of DPC and APC, respectively. Furthermore, as in Studies 1 and 2, we examined mean-level gender differences in DPC and APC. We also examined the possibility that the associations between DPC, APC, and adolescent vulnerability to depression may differ by parent and adolescent gender. With respect to parental gender, Blatt and Homann (1992) have suggested that mothers would be more important in the development of dependency than fathers. In contrast, both mothers and fathers would be involved in the development of self-criticism. Research has provided some evidence for Blatt and Homann's expectations about the differential roles of mothers and fathers (e.g., McCranie \& Bass, 1984). Accordingly, it was anticipated that, whereas perceived APC by both mothers and fathers would relate to adolescent self-criticism, the relation between DPC and dependency would be more pronounced for maternal ratings than for paternal ratings. In this context, we also explored whether adolescent gender would moderate the associations between the domains of psychological control and vulnerability to depression.

\section{Method}

\section{Participants and Procedure}

Participants were 451 middle adolescents from two secondary schools in Belgium. One participant was removed from this sample because he was 22 years old and this study aimed to sample middle adolescents. The age of the remaining participants ranged from 15 to 19 , with a mean of 16.63 years $(S D=0.90)$. There were $332(74 \%)$ girls and $118(26 \%)$ boys in the sample. This unbalanced gender distribution was not due to a self-selective bias in the sampling procedure; rather, it mirrored the distribution in the student population of the two schools involved in this study. A total of 171 students were in 10 th grade $(38 \%), 163$ students were in 11 th grade 
$(37 \%)$, and 113 students were in 12 th grade $(25 \%)$. Concerning family structure, $83 \%$ of the adolescents came from intact families, $13 \%$ had divorced parents, and $4 \%$ came from a family in which one of the parents had deceased. All participants were White and of Belgian nationality. The questionnaires for adolescents were administered to the students during a class period, and at least one of the primary researchers of this project was present during data collection. The students had approximately $45 \mathrm{~min}-$ utes to complete the surveys. Participation was voluntary and anonymity was guaranteed.

\section{Measurements}

$D P C$ and APC. Participants were administered the DAPCS developed in Study 1. The scales were rated for mothers and fathers separately. Cronbach's $\alpha$ of the DPC scale was .85 and .76 for mothers and fathers, respectively. Cronbach's $\alpha$ of the APC scale was .92 and .88 for mothers and fathers, respectively.

Dependency and self-criticism. The Depressive Experiences Questionnaire for Adolescents (DEQ-A; Blatt, Schaffer, Bers, \& Quinlan, 1992) is a 66-item questionnaire tapping dependency, self-criticism, and efficacy. This questionnaire is based on Blatt, D'Afflitti, and Quinlan's (1976) original adult version of the DEQ. Items of the adult DEQ were modified to better fit with adolescents' experiential world. It has been shown that the DEQ-A has a stable factor structure, adequate test-retest reliability, and good validity, as evidenced by relations with measures of depressive symptoms and psychopathology in general (e.g., Blatt et al., 1992; Leadbeater, Kuperminc, Blatt, \& Hertzog, 1999). Scores for dependency and self-criticism were derived using the factor scoring procedure proposed by Blatt et al. (1992). The efficacy scale was not used in this study because it taps positive feelings of competence rather than vulnerability to depression.

Depressive symptoms. Participants filled out the 12-item CES-D described in Study 2. Cronbach's $\alpha$ was .86 .

\section{Results}

Preliminary Analyses

CFA. As in Study 1, CFA showed that a two-factor solution, $\chi^{2}(118)=320.29$, RMSEA $=.06$, SRMR $=.05, \mathrm{CFI}=.98$, for maternal ratings and $\chi^{2}(118)=227.99, \mathrm{RMSEA}=.05, \mathrm{SRMR}=.05$, $\mathrm{CFI}=.98$, for paternal ratings, fit the data better than a one-factor 
solution, $\chi^{2}(119)=875.44, \mathrm{RMSEA}=.12, \mathrm{SRMR}=.09, \mathrm{CFI}=.93$, for maternal ratings and $\chi^{2}(119)=397.92, \mathrm{RMSEA}=.07, \mathrm{SRMR}=$ $.07, \mathrm{CFI}=.96$, for paternal ratings, as evidenced by a significant difference in chi-square, $\Delta \chi^{2}=555.15, d f=1, p<.001$, for maternal ratings and $\Delta \chi^{2}=169.93, d f=1, p<.001$ for paternal ratings. Standardized factor loadings in the maternal solution ranged from .54 to .83 (all $p \mathrm{~s}<.001$ ) with a mean of .71 , and loadings in the paternal solution ranged from .45 to .82 (all $p \mathrm{~s}<.001)$ with a mean of .62 . Reliability estimates according to Leone et al.'s (2001) formula for maternal DPC and APC were .85 and .93, respectively. Reliability estimates for paternal DPC and APC were .77 and .89, respectively.

Descriptives. Descriptive statistics for the study variables are provided in Table 5. As in Studies 1 and 2, mean-level parent and adolescent gender differences in DPC and APC were examined by means of a repeated measures MANOVA. A significant multivariate effect was obtained for parental gender, Wilks $\lambda=0.90, F(2$, $439)=23.47, p<.001, \eta^{2}=.10$, and for adolescent gender, Wilks $\lambda=0.94, F(2,439)=15.42, p<.01, \eta^{2}=.07$. The interaction between parent and adolescent gender was not significant, Wilks $\lambda=0.99, F(2,439)=3.39, p>.01, \eta^{2}=.02$. Univariate ANOVAs indicated effects of parental gender on DPC, $F(1,440)=25.25$, $p<.001, \eta^{2}=.05$, and APC, $F(1,440)=4.21, p<.05, \eta^{2}=.01$.

\section{Table 5}

Descriptive Statistics and Correlations Between Study Variables (Study 3)

\begin{tabular}{lrrrrrrrrr}
\hline Variable & $M$ & $S D$ & 1 & 2 & 3 & 4 & 5 & 6 & 7 \\
\hline 1. Maternal DPC & 1.98 & 0.73 & & & & & & \\
2. Maternal APC & 1.73 & 0.79 & $.59^{* *}$ & & & & & \\
3. Paternal DPC & 1.75 & 0.59 & $.49^{* * *}$ & $.35^{* *}$ & & & & \\
4. Paternal APC & 1.81 & 0.73 & $.37^{* * *}$ & $.50^{* * *}$ & $.59^{* * *}$ & & & \\
5. Dependency & -0.11 & 0.86 & $.31^{* *}$ & $.15^{*}$ & .05 & .01 & & \\
6. Self-criticism & -0.01 & 0.91 & $.27^{* *}$ & $.33^{* *}$ & $.22^{* *}$ & $.30^{* *}$ & -.08 & \\
7. Depressive symptoms & 0.81 & 0.53 & $.29^{* * *}$ & $.26^{* *}$ & $.14^{*}$ & $.24^{* *}$ & $.35^{* * *} .46^{* * *}$
\end{tabular}

Note: $\mathrm{DPC}=$ dependency-oriented psychological control, $\mathrm{APC}=$ achievementoriented psychological control.

${ }^{*} p<.01 .{ }^{* *} p<.001$. 
Whereas mothers were rated as higher on DPC $(M=1.98$, $S D=0.73)$ compared to fathers $(M=1.75, S D=0.59)$, fathers were rated as higher on APC $(M=1.81, S D=0.73)$ compared to mothers $(M=1.74, S D=0.79)$. Adolescent gender had an effect on DPC, $F(1,440)=9.73, p<.01, \eta^{2}=.02$, and on APC, $F(1,440)=$ $24.83, p<.001, \eta^{2}=.07$. Males reported higher DPC $(M=2.01$, $S D=0.68)$ and higher APC $(M=2.05, S D=0.78)$ than females $(M=1.82, S D=0.62$ and $M=1.67, S D=0.73$, respectively $)$.

We examined effects of adolescent gender on dependency, selfcriticism, and depressive symptoms by means of another MANOVA. A significant multivariate effect was obtained, Wilks $\lambda=0.90, F(3$, $435)=16.61, p<.001, \eta^{2}=.10$. Univariate ANOVAs indicated effects of adolescent gender on dependency, $F(1,437)=32.91$, $p<.001, \eta^{2}=.07$, self-criticism, $F(1,437)=12.30, p<.001, \eta^{2}=.03$, and depressive symptoms, $F(1,437)=5.06, p<.05, \eta^{2}=.01$. Female adolescents scored higher on dependency $(M=0.03, S D=0.81)$ and depressive symptoms $(M=0.84, S D=0.54)$ compared to male adolescents $(M=-0.49, S D=0.89$ and $M=0.71, S D=0.50$, respectively). Conversely, male adolescents obtained higher scores on selfcriticism $(M=0.25, S D=0.85)$ compared to female adolescents $(M=-0.09, S D=0.91)$. Adolescent age was not significantly related to any of the study variables (all $p \mathrm{~s}>.05$ ).

\section{Primary Analyses}

Correlations. Correlations between the study variables are provided in Table 5. As in Study 1, we found substantial correlations between the domain-specific scales of psychological control and between maternal and paternal ratings of each scale. Whereas maternal DPC was positively related to dependency, paternal DPC was not. Both maternal and paternal APC were positively related to self-criticism and to a lesser extent to dependency. Dependency and selfcriticism were positively related to depressive symptoms.

Structural equation modeling (SEM). The primary hypotheses of this study were examined by means of SEM with manifest variables. Models were estimated separately for mothers and fathers. The covariance matrices were used as input, and solutions were generated on the basis of maximum-likelihood estimation. The modeling procedure proceeded in two steps. First, we examined direct effects of 
DPC and APC on depressive symptoms by entering both domains of psychological control simultaneously in the prediction of depressive symptoms. This model is a fully saturated model because all possible associations between the three constructs involved are specified. Second, we estimated the hypothesized mediation model including paths from DPC to dependency, from APC to self-criticism, and from both dependency and self-criticism to depressive symptoms. In both models, gender was added as a control variable by allowing paths from gender to each of the model constructs.

In the maternal data, the direct effects model yielded independent significant effects of DPC $(\beta=.21, p<.01)$ and APC $(\beta=.18$, $p<.01)$ on depressive symptoms, controlling for the effect of gen$\operatorname{der}(\beta=.22, p<.01)$. Next, estimation of the hypothesized mediation model yielded an acceptable model fit, $\chi^{2}(4)=10.01$, RMSEA $=.06$, $\mathrm{SRMR}=.04, \mathrm{CFI}=.99$, and all hypothesized path coefficients were significant $(p<.01)$. Adding paths from DPC to self-criticism and from APC to dependency did not improve model fit, and both paths ( $\beta=.07$ and .14 , respectively) were not significant ( $p s>.05)$, a finding that supports the hypothesized specificity of the relations between DPC and APC and the two vulnerability factors. Further, adding direct paths from DPC and APC to depressive symptoms also did not improve model fit, and both effects $(\beta=.02$ and .09 , respectively) were not significant. The latter findings demonstrate that the initial direct effects of DPC and APC on depressive symptoms are reduced to nonsignificance after we enter dependency and self-criticism as intervening variables. In other words, the effects of DPC and APC were fully and differentially mediated by dependency and self-criticism, as further indicated by the significant indirect effects of both DPC $(z=4.85, p<.001)$ and APC $(z=4.97, p<.001)$ on depressive symptoms through these intervening variables. Figure 1 shows the final model for the maternal ratings.

In the paternal data, the direct effects model yielded a significant effect of APC $(\beta=.30, p<.001)$ on depressive symptoms even when we controlled for gender $(\beta=.24, p<.01)$. The effect of DPC, however, was not significant $(\beta=.03, p>.05)$. Estimation of the hypothesized mediation model yielded an acceptable model fit, $\chi^{2}(4)=12.70$, RMSEA $=.07$, SRMR $=.04, \mathrm{CFI}=.98$, and all hypothesized path coefficients were significant $(p<.01)$. Adding paths from DPC to selfcriticism and from APC to dependency did not improve model fit, and both paths (both $\beta s=.04$ ) were not significant $(p s>.05$ ). Adding a 


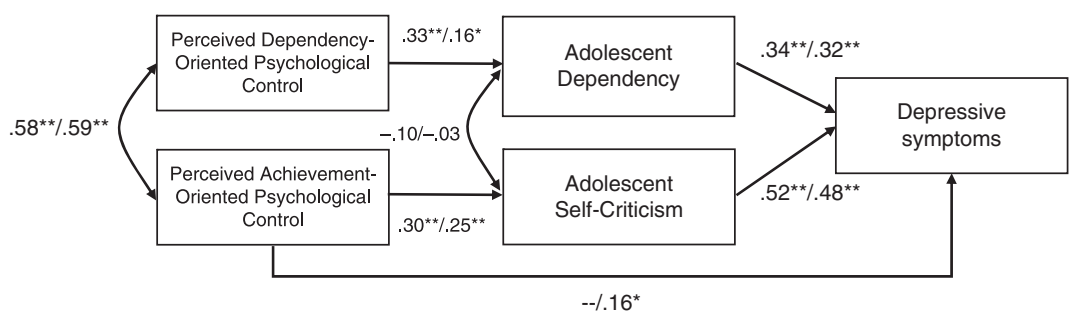

Figure 1

Structural model of relations between perceived DPC, APC, dependency, self-criticism, and depressive symptoms (Study 3). Coefficients shown are standardized path coefficients. The first coefficient refers to the maternal model, and the second coefficient refers to the paternal model. For clarity of presentation, the effects of gender are not shown. $* p<.01 . * * p<.001$.

direct path from DPC to depressive symptoms did not improve model fit, and this effect $(\beta=-.03)$ was not significant. Although DPC did not have an initial effect on depressive symptoms (and thus could not be mediated by dependency), it was still deemed useful to examine the indirect effect of DPC on depression through dependency. Even in the absence of a significant direct association, an independent variable may still be indirectly related to a dependent variable through its effect on the intervening variable (MacKinnon, Lockwood, Hoffman, West, $\&$ Sheets, 2002). The indirect effect of DPC through dependency on depressive symptoms was significant $(z=2.82, p<.01)$, indicating that the association between DPC and depressive symptoms is indirect rather than mediated. Further, adding a direct effect from APC to depressive symptoms did improve model fit, and this direct effect was significant $(\beta=.16, p<.01)$. Note, however, that the latter effect was substantially reduced compared to its original size (i.e., from .30 to .16). Moreover, the indirect effect of APC to depressive symptoms through self-criticism was significant $(z=4.36, p<.001)$, indicating that the association between APC and depressive symptoms was partially mediated by self-criticism. The final best-fitting model for the paternal ratings is depicted in Figure 1.

One unexpected finding in Figure 1 is the significant path from paternal DPC to adolescent dependency. This path is striking because the raw correlation between paternal DPC and dependency was not significant. The hypothesized association between DPC and dependency thus seems less consistently supported for paternal DPC than 
for maternal DPC (which was positively related to dependency, both in the correlations and in the path analysis). Moreover, because Blatt and Homann (1992) formulated explicit hypotheses about the differential role of mothers and fathers in the development of dependency, we performed an ancillary set of regression analyses where maternal and paternal DPC were simultaneously entered as predictors of dependency. It was found that, after we controlled for the effect of gender, only maternal DPC $(\beta=.34, p<.001)$ but not paternal DPC $(\beta=-.05, p<.01)$ significantly predicted dependency. A similar regression analysis was performed to examine the relative contribution of maternal and paternal APC to the prediction of self-criticism. It was found that maternal APC $(\beta=.23, p<.001)$ and paternal APC $(\beta=.17, p<.01)$ explained independent variance in self-criticism.

Multigroup analysis. To examine whether adolescent gender moderates the associations in the mediation model (Figure 1), multigroup analyses were performed. These analyses were performed on the final best fitting models for the maternal and paternal data depicted in Figure 1 because these models contained all the paths relevant to this study. Multigroup analysis compares a constrained model, that is, a model in which the structural coefficients are set equal across gender, to an unconstrained model, that is, a model in which these coefficients are allowed to vary between males and females. The constrained and the unconstrained models are compared in terms of the chi-square difference corresponding to the number of degrees of freedom. A significant difference implies that the model differs significantly across gender. In contrast, a nonsignificant difference implies that the model holds invariantly across groups. No significant differences were found between the constrained and the unconstrained models in both the maternal data, SBS- $\chi_{\text {diff }}^{2}(4)=4.63$, $p>.05$, and the paternal data, $\operatorname{SBS}-\chi_{\text {diff }}^{2}(5)=8.67, p>.05$, indicating that adolescents' gender does not moderate the structural relationships in the models.

Curvilinear associations. In a final set of ancillary analyses, we tested for the possibility that associations between the domains of psychological control and the adolescent outcomes would be curvilinear rather than linear in nature. One may wonder, for instance, whether psychological control is primarily or only problematic at high or extreme levels. To test for curvilinear effects, we centered the 
scores on DPC and APC and computed quadratic terms on the basis of these centered scores. In a set of regression analyses we examined whether the quadratic terms added to the prediction beyond the effect of the (centered) main effects of DPC and APC. Regression analyses were performed separately for maternal and paternal ratings of psychological control and separately for achievement-oriented psychological control and dependency-oriented psychological control. This resulted in a total of 12 regression analyses ( 4 for each of the three dependent variables). Only 1 out of 12 quadratic terms reached significance, that is, the quadratic term of maternal achievement-oriented psychological control in the prediction of adolescent dependency $(\beta=.12, p=.04)$. Follow-up analyses, where individuals were categorized into a low, medium, and high category on the basis of a tertile split on the scores for maternal achievement-oriented psychological control, did not reveal significant differences between the three categories in terms of adolescent dependency. Given the overall lack of quadratic effects, it seems that relations between the domains of psychological control and the adolescent outcomes are linear rather than curvilinear in nature.

\section{DISCUSSION}

This series of studies aimed to validate a distinction between two domain-specific expressions of parental psychological control. Developmental theory and research suggested the possibility that some forms of pressuring parenting are driven by concerns about parentchild distancing whereas others are driven by performance-related concerns. The present study, however, is the first to explicitly test the idea of a distinction between dependency-oriented psychological control and achievement-oriented psychological control.

Internal and External Validity of the Distinction Between DPC and $A P C$

Factor analyses showed that the distinction between DPC and APC holds in both middle and late adolescents' perceptions' of their parents as well as in parents' own perceptions of their rearing behavior. The two domain-specific expressions of psychological control were substantially correlated (average $r$ across the three studies $=.55$ ), which makes sense, given that they both represent instantiations of a 
pressuring and intrusive parenting style. The size of these correlations suggests that parents who use psychological control in one domain are likely to also use psychological control in the other domain. Yet, given that the correlation between DPC and APC is far from perfect, it seems plausible that, whereas some parents may score high (or low) on psychological control in both domains simultaneously, other parents' rearing style may be predominantly characterized by psychological control in one domain and to a lesser extent by psychological control in the other domain. Future research using a person-oriented approach may attempt to identify such differentiated profiles. In general, it is important to note that the mean scores on DPC and APC were quite low, indicating that parents are not perceived as highly controlling, at least not in the community samples studied here. In spite of the low mean on these dimensions, there was substantial variability in scores on DPC and APC and, as will be detailed below, this variability was related in theoretically meaningful ways to parental and adolescent variables.

The distinction between DPC and APC was externally validated by relating both expressions of psychological control to well-established measures of perceived family climate and parenting style. First, as expected, DPC and APC were related to a similar extent to perceptions of parents as psychologically controlling and autonomy suppressing. Supporting the divergent validity of the distinction between DPC and APC, both expressions of psychological control were differentially related to a measure of parental support, such that only APC was uniquely related to perceptions of parents as uninvolved cold, distant, and unresponsive to distress. Given that APC involves an orientation where parents hold relentless achievement standards for their children, APC is indeed likely to go together with a cold and aloof parental attitude toward their children. Conversely, the finding that, after we controlled for the variance shared with APC, DPC is unrelated (in the maternal ratings) or even positively related (in the paternal ratings) to parental support indicates that DPC is less consistently related to experiences of parents as cold and unresponsive. Given that DPC involves an intolerance for parent-child distance, it seems logical that DPC will at times go together with displays of concern, care, and involvement. On the other hand, the involvement associated with DPC is conditional in nature such that warmth and love are only provided when the child remains within close parent-child boundaries. 
Second, DPC and APC were also differentially related to measures of enmeshed and perfectionist family climates. Whereas the constructs of DPC and APC are to be situated at the level of the parent-child dyads, the constructs of enmeshment and family perfectionism pertain to the interpersonal climate at the level of the family as a whole. As expected, DPC was uniquely related to enmeshment, indicating that DPC is most common in families characterized by inadequate boundaries (Barber \& Buehler, 1996; Green $\&$ Werner, 1996). Also as expected, APC was uniquely associated with a perfectionist family climate. Perfectionist families are characterized by an atmosphere of demanding standards for achievement, where family members are compared and evaluated in terms of their performance in school, at work, or in sports (Frost et al., 1990).

\section{Gender Differences}

Research on gender differences in parental psychological control has typically relied on general measures of psychological control. Barber and Harmon (2002) concluded that there is a trend for mothers to score higher on measures of psychological control than fathers. Also, male adolescents score somewhat higher on psychological control compared to female adolescents. The findings on gender differences in previous research are far from consistent, however, and the magnitude of the gender differences obtained is typically small.

Herein, we argue that the distinction between DPC and APC may allow for a more fine-grained and theoretically driven analysis of gender differences in psychological control. It has indeed been argued from diverse conceptual accounts that females are more strongly socialized and oriented toward relationships and belongingness, whereas males are more strongly oriented toward individual achievement, self-assertion, and independence (e.g., Blatt \& Shichman, 1983; Josselson, 1987), at least in contemporary Western cultures. Given these gender-specific orientations, we hypothesized that mothers' use of psychological control is more likely to center around interpersonal issues (i.e., DPC), whereas fathers' use of psychological control primarily involves issues of achievement (i.e., APC). Consistent with this hypothesis, we found that adolescents systematically rated their mothers as higher on DPC than their fathers. This gender difference did not show up in mothers' self-reports of DPC, although 
mothers did rate themselves as higher on separation anxiety than fathers. Conversely, fathers were perceived as higher on APC than mothers and also reported themselves to use more APC than mothers did. Overall then, our data reveal a clear tendency for mothers' psychological control to center primarily around issues of parentchild distance and for fathers' psychological control to primarily involve achievement-related concerns. Thus, the lack of consistent parent gender differences in psychological control obtained in previous research might be due to the lack of domain differentiation in the assessment of psychological control.

Less consistent evidence was found for the idea that female adolescents would experience more DPC than male adolescents and that male adolescents would experience more APC than female adolescents. Specifically, although males reported higher levels of APC than females, females did not report higher levels of DPC than males. Unexpectedly, in Study 3 males scored even higher than females on DPC. Although these findings provide only partial support for our hypothesis, they do suggest the interesting possibility that the higher levels of psychological control reported by males in previous research are uniquely due to the higher levels among males of one expression of psychological control (i.e., APC). It remains unclear why we did not obtain the anticipated gender differences in DPC, and this requires further research. More generally, it should be noted that parental gender differences were more consistent and systematically larger than adolescent gender differences.

\section{Antecedents and Outcomes of DPC and APC}

In line with our expectations, we found that DPC and APC were differentially related to features of parents' personality functioning. Parental separation anxiety was uniquely related to DPC. Parents who experience events signaling parent-child distance as threatening and who anticipate their child's increasing independence with feelings of resentment and anxiety thus report using more psychologically controlling tactics to keep their child within close physical and emotional boundaries (Hock et al., 2001; Soenens et al., 2006). Parental maladaptive perfectionism, in contrast, was uniquely related to APC. This finding is consistent with the reasoning that perfectionist parents project their own standards onto their children and use manipulative pressure as a means to impose their achievement- 
oriented standards on their children (Flett et al., 2002; Grolnick, 2003; Soenens, Elliot, et al., 2005).

It is important to note that this study focused on only one possible source of psychological control, that is, parent personality functioning. Given that parenting is multiply determined, an important avenue for future research is to additionally examine social-contextual factors and child behaviors as possible determinants (Barber et al., 2005). It is possible, for instance, that premature adolescent detachment from parents may specifically elicit concerns about parentchild distancing (as expressed in DPC), whereas academic failure may elicit concerns about achievement (as expressed in APC). Most likely, the domain-specific expressions of psychological control result from a complex and transactional interaction between adolescent functioning and parent personality.

Our findings also suggest that both expressions of psychological control, in addition to being rooted in different parental antecedents, are related to adolescent distress through differential pathways. DPC was found to be specifically related to adolescent dependency, and this association was more pronounced for mothers than for fathers. According to Blatt (1974; Blatt \& Homann, 1992), a parenting style where parents (and mothers in particular) use their love to pressure the child to remain within close proximity (e.g., through love withdrawal) indeed represents one of the major pathways through which a dependent vulnerability can develop. As a consequence of such a parenting style, children would become insecure and anxious about their parents' love, an orientation that would be repeated in relationships other than the parent-child dyad. Dependent individuals thus need constant affirmation that others are available, develop a clinging interpersonal style, and experience deep-seated anxiety about separation. It is interesting to note that Blatt and Homann hypothesized that mothers would be more strongly involved in the development of dependency than fathers. From a psychoanalytic perspective, dependency primarily deals with oral issues such as fear of losing an object's nurturance and care. Given that mothers are typically more salient socialization figures in these early stages of development, mothers' parenting style would be more strongly predictive of dependency than fathers' parenting style. Consistent with this reasoning, maternal DPC was more consistently related to dependency than paternal DPC. However, given that this is a first study on DPC and dependency, these 
findings are preliminary, and additional research is needed to confirm them.

Also consistent with the theory of Blatt, APC was specifically related to adolescent self-criticism. Self-criticism is thought to develop when parents make their approval contingent upon meeting strict parental standards and when they induce guilt for performing less than perfectly. As a consequence, children would become anxious about failing to meet parental standards and would develop a tendency to criticize themselves for failing to meet self-imposed standards (Blatt \& Homann, 1992). Both maternal and paternal APC were found to relate to self-criticism and even explained independent variance in self-criticism. This finding, which suggests that both mothers and fathers may contribute to the development of self-criticism, is again in line with psychoanalytic theory. Self-criticism mainly deals with issues from the oedipal stages of development (e.g., guilt; Blatt, 1974). Consistent with the notion that relationships in this stage become increasingly triadic and that both parents are involved in the negotiation of the oedipal transition, Blatt and Homann reasoned that the relationship with both parents is crucial in the development of a self-critical orientation.

As in previous studies, dependency and self-criticism explained independent variance in adolescents' depressive symptoms, with selfcriticism emerging as a somewhat stronger predictor (Blatt et al., 1992) and, moreover, served as differential mediators in relations between DPC, APC, and depressive symptoms. This model of differential mediation was found to be consistent across adolescent gender, thereby testifying to its stability and generalizability. Finally, it is interesting to note that the relations between the domains of psychological control, dependency, self-criticism, and depressive symptoms were generally linear rather than curvilinear in nature. This is in line with Blatt's notion of continuity between normal functioning and psychopathology (Blatt, 2004). Contrary to the idea that there is a clear demarcation between depressive symptoms and a clinical diagnosis of major depressive disorder (as is implied in the DSM-IV taxonomy), Blatt (2004) assumed that depressive symptoms are continuous with a clinical diagnosis of depression. This position is rooted in Blatt's broader theory of personality development, which conceives psychopathology as a gradual deviation from the normal dialectical interaction between two fundamental developmental lines (i.e., the interpersonal and self-definition lines). Given such a 
continuous view on depression, one would indeed expect to find linear associations between factors that may create a vulnerability to depression (e.g., controlling parenting) and depressive symptoms.

Given the maladaptive outcomes associated with DPC and APC in this study, one may wonder about a more positive alternative to these expressions of psychological control. Conceptually speaking, the opposite of psychologically controlling parenting is autonomysupportive parenting (Grolnick, 2003). Instead of pressuring children into activities and aspirations that fit with parents' own agenda, autonomy-supportive parents would take their children's perspective, allow choices whenever possible, and refrain from controlling language (Grolnick, 2003). Research has shown that autonomy-supportive parenting yields numerous benefits in terms of children's well-being and adaptive behavior. Yet the potential role of parental autonomy support as a protective factor against (adolescent) depression remains understudied. Thus, future research would do well to simultaneously examine parental autonomy support and the domains of psychological control to further our understanding of the relations among these constructs and their differential relations to susceptibility to depression.

\section{Limitations}

A number of limitations of this series of studies should be noted. First and foremost, the evidence for the differential antecedents and outcomes of DPC and APC reported here is cross-sectional in nature. Longitudinal research is needed to examine these presumed processes in a more dynamic fashion and, in particular, to allow for a more appropriate test of the causal ordering of the study constructs assumed in this model.

A second limitation is the use of self-reports to measure DPC and APC. Although the validity of the DAPCS was shown using both adolescent and parent reports, some of the findings obtained within each of the studies may be attenuated by shared method variance. Future studies may simultaneously include parent and adolescents reports of DPC and APC and use the variance shared by both types of reports as a more valid assessment of DPC and APC (e.g., Soenens et al., 2006). The inclusion of both parents and adolescents into a single study may also allow researchers to examine whether parental features such as dependency/separation anxiety and self- 
criticism/perfectionism are transmitted from one generation to the next through the effects of DPC and APC (Besser \& Priel, 2005; Elliot \& Thrash, 2004; Soenens, Elliot, et al., 2005). In addition, studies may include additional sources of information to measure both the antecedents (e.g., partner reports of separation anxiety and perfectionism) and outcomes (e.g., clinician or teacher ratings of internalizing problems) of DPC and APC.

Third, we examined our hypotheses in relatively homogeneous samples of well-educated and White adolescents and parents. A specific concern in Study 2 is the high educational level of parents, which is a likely consequence of the recruitment procedure used in that study. As such, the generalizability of our findings to samples that are more diverse in terms of socioeconomic status, educational background, and ethnicity remains to be examined. Comparisons of our findings with those obtained in nations with a different family culture are of particular importance. On the basis of the mounting evidence that psychologically controlling parenting forecasts adverse developmental outcomes in nations across the globe (Wang, Pomerantz, \& Chen, 2007), we anticipate that, in spite of possible meanlevel differences in terms of DPC and APC, the effects and dynamics associated with both expressions of psychological control may generalize across cultures. Additionally, given that the means on the DPC and APC scales were quite low in the current samples of normal adolescents and parents, future research may examine the effects of DPC and APC in clinical samples. This would allow one to examine (a) whether scores on the domains of psychological control are elevated in clinical samples and (b) whether the structural relations between the domains of psychological control, dependency, self-criticism, and severity of psychopathology apply to samples with elevated levels of psychological control. On the basis of extant research (e.g., Soenens et al., 2008), we expect a high level of similarity in the structural relations obtained with clinical and nonclinical samples.

\section{Conclusion}

On the basis of Blatt's (2004) theory of personality development, we tested the idea that psychological control can center around two distinct yet fundamental issues, that is, (a) issues of relatedness, separation, and parent-child distance, and (b) issues of achievement, 
performance, and perfection. Parents' use of psychological control in these two domains is differentially related to features of parents' own personality functioning. Moreover, although parents' use of psychological control in both domains may render adolescents vulnerable to internalizing problems and to depressive symptoms in particular, they seem to do so along distinct developmental pathways.

\section{REFERENCES}

Amitay, O. A., Mongrain, M., \& Fazaa, N. (2008). Love and control: Self-criticism in parents and daughters and their perceptions of relationship partners. Personality and Individual Differences, 44, 75-85.

Barber, B. K. (1996). Parental psychological control: Revisiting a neglected construct. Child Development, 67, 3296-3319.

Barber, B. K., \& Buehler, C. (1996). Family cohesion and enmeshment: Different constructs, different effects. Journal of Marriage and the Family, 58, 433-441.

Barber, B. K., \& Harmon, E. L. (2002). Violating the self: Parental psychological control of children and adolescents. In B. K. Barber (Ed.), Intrusive parenting: How psychological control affects children and adolescents (pp. 15-52). Washington, DC: American Psychological Association.

Barber, B. K., Stolz, H. E., \& Olsen, J. A. (2005). Parental support, psychological control, and behavioral control: Assessing relevance across time, method, and culture. Monographs of the Society for Research in Child Development, 70 (7, Serial No. 276).

Besser, A., \& Priel, B. (2005). The apple does not fall far from the tree: Attachment styles and personality vulnerabilities to depression in three generations of women. Personality and Social Psychology Bulletin, 31, 1052-1073.

Blatt, S. J. (1974). Levels of object representation in anaclitic and introjective depression. Psychoanalytic Study of the Child, 29, 107-157.

Blatt, S. J. (2004). Experiences of depression: Theoretical, clinical, and research perspectives. Washington, DC: American Psychological Association.

Blatt, S. J., D'Afflitti, J. P., \& Quinlan, D. M. (1976). Experiences of depression in normal young adults. Journal of Abnormal Psychology, 85, 383-389.

Blatt, S. J., \& Homann, E. (1992). Parent-child interaction in the etiology of depression. Clinical Psychology Review, 12, 47-91.

Blatt, S. J., Schaffer, C. E., Bers, S. A., \& Quinlan, D. M. (1992). Psychometric properties of the Depressive Experiences Questionnaire for Adolescents. Journal of Personality Assessment, 59, 82-98.

Blatt, S. J., \& Shichman, S. (1983). Two primary of configurations of psychopathology. Psychoanalysis and Contemporary Thought, 6, 187-254.

Bloom, B. L. (1985). A factor analysis of self-report measures of family functioning. Family Process, 24, 225-239.

Buehler, C., Benson, M. J., \& Gerard, J. M. (2006). Interparental hostility and early adolescent problem behavior: The mediating role of specific aspects of parenting. Journal of Research on Adolescence, 16, 265-292. 
Elliot, A. J., \& Thrash, T. M. (2004). The intergenerational transmission of fear of failure. Personality and Social Psychology Bulletin, 30, 957-971.

Flett, G. L., Hewitt, P. L., Oliver, J. M., \& MacDonald, S. (2002). Perfectionism in children and their parents: A developmental analysis. In G. L. Flett \& P. L. Hewitt (Eds.), Perfectionism: Theory, research, and treatment (pp. 89-132). Washington, DC: American Psychological Association.

Frost, R. O., Marten, P., Lahart, C. M., \& Rosenblate, R. (1990). The dimensions of perfectionism. Cognitive Therapy and Research, 14, 449-468.

Green, R. J., \& Werner, P. D. (1996). Intrusiveness and closeness-caregiving: Rethinking the concept of family enmeshment. Family Process, 35, 115-136.

Grolnick, W. S. (2003). The psychology of parental control: How well-meant parenting backfires. Mahwah, NJ: Erlbaum.

Grolnick, W. S., Price, C. E., Beiswenger, K., \& Sauck, C. C. (2007). Evaluative pressure in parents: Effects of situation, maternal, and child characteristics on autonomy-supportive versus controlling behavior. Developmental Psychology, 43, 991-1002.

Grolnick, W. S., Ryan, R. M., \& Deci, E. L. (1991). The inner resources for school performance: Motivational mediators of children's perceptions of their parents. Journal of Educational Psychology, 83, 508-517.

Henson, R. K., \& Roberts, J. K. (2006). Use of exploratory factor analysis in published research. Educational and Psychological Measurement, 66, 393-416.

Hock, E., Eberly, M., Bartle-Haring, S., Ellwanger, P., \& Widaman, K. (2001). Separation anxiety in parents of adolescents: Theoretical significance and scale development. Child Development, 72, 284-298.

Hu, L., \& Bentler, P. M. (1999). Cutoff criteria for fit indexes in covariance structure analysis: Conventional criteria versus new alternatives. Structural Equation Modeling, 6, 1-55.

Jöreskog, K. G., \& Sörbom, D. (1996). LISREL 8: Structural equation modeling with the SIMPLIS command language. Chicago: Scientific Software International.

Josselson, R. (1987). Finding herself: Pathways to identity development in women. San Francisco: Jossey-Bass.

Kenney-Benson, G. A., \& Pomerantz, E. M. (2005). The role of mothers' use of control in children's perfectionism: Implications for the development of depressive symptoms. Journal of Personality, 73, 23-46.

Koestner, R., Zuroff, D.C, \& Powers, T. A. (1991). The family origins of adolescent self-criticism and its continuity into adulthood. Journal of Abnormal Psychology, 100, 191-197.

Leadbeater, B. J., Kuperminc, G. P., Blatt, S. J., \& Hertzog, C. (1999). A multivariate model of gender differences in adolescents' internalizing and externalizing problems. Developmental Psychology, 35, 1268-1282.

Leone, L., Perugini, M., Bagozzi, R. P., Pierro, A., \& Mannetti, L. (2001). Construct validity and generalizability of the Carver-White Behavioral Inhibition System/Behavioral Activation System Scales. European Journal of Personality, 15, 373-390. 
Luyten, P., Blatt, S. J., Van Houdenhove, B., \& Corveleyn, J. (2006). Depression research and treatment: Are we skating to where the puck is going to be? Clinical Psychology Review, 26, 985-999.

MacKinnon, D. P., Lockwood, C. M., Hoffman, J. M., West, S. G., \& Sheets, V. (2002). A comparison of methods to test mediation and other intervening variable effects. Psychological Methods, 7, 83-104.

Manzi, C., Vignoles, V. L., Regalia, C., \& Scabini, E. (2006). Cohesion and enmeshment revisited: Differentiation, identity, and well-being in two European cultures. Journal of Marriage and Family, 68, 673-689.

McArdle, S., \& Duda, J. L. (2005). Exploring social-contextual correlates of perfectionism in adolescents: A multivariate perspective. Cognitive Therapy and Research, 28, 765-788.

McCranie, E. W., \& Bass, J. D. (1984). Childhood family antecedents of dependency and self-criticism: Implications for depression. Journal of Abnormal Psychology, 93, 3-8.

Mongrain, M. (1998). Parental representations and support-seeking behaviors related to Dependency and Self-Criticism. Journal of Personality, 66, 91-113.

Parker, G. (1983). Parental overprotection: A risk factor in psychosocial development. New York: Grune \& Stratton.

Pettit, G. S., \& Laird, R. D. (2002). Psychological control and monitoring in early adolescence: The role of parental involvement and earlier child adjustment. In B. K. Barber (Ed.), Intrusive parenting: How psychological control affects children and adolescents (pp. 97-124). Washington, DC: American Psychological Association.

Radloff, L. S. (1977). The CES-D scale: A self-report depression scale for research in the general population. Applied Psychological Measurement, 1, 385-401.

Roberts, R. E., \& Sobhan, M. (1992). Symptoms of depression in adolescence: A comparison of Anglo, African, and Hispanic Americans. Journal of Youth and Adolescence, 21, 639-651.

Roth, G., Assor, A., Niemiec, C. P., Ryan, R. M., \& Deci, E. L. (2009). The emotional and academic consequences of parental conditional regard: Comparing conditional positive regard, conditional negative regard, and autonomy support as parenting practices. Developmental Psychology, 45, 1119-1142.

Schaefer, E. S. (1965). Children's reports of parental behavior: An inventory. Child Development, 36, 413-424.

Schluterman, J. A. (2007). The social ecology of parenting: Systematically modeling the antecedents of supportive and intrusive parenting. Unpublished doctoral dissertation, University of Tennessee, Knoxville.

Soenens, B., Elliot, A. J., Goossens, L., Vansteenkiste, M., Luyten, P., \& Duriez, B. (2005). The intergenerational transmission of perfectionism: Parents' psychological control as an intervening variable. Journal of Family Psychology, 19, 358-366.

Soenens, B., Vansteenkiste, M., Duriez, B., \& Goossens, L. (2006). In search of the sources of psychologically controlling parenting: The role of parental separation anxiety and parental maladaptive perfectionism. Journal of Research on Adolescence, 16, 539-559. 
Soenens, B., Vansteenkiste, M., Luyten, P., Duriez, B., \& Goossens, L. (2005). Maladaptive perfectionistic self-representations: The mediational link between psychological control and adjustment. Personality and Individual Differences, 38, 487-498.

Soenens, B., Vansteenkiste, M., Vandereycken, W., Luyten, P., Sierens, E., \& Goossens, L. (2008). Perceived parental psychological control and eating disordered symptoms: Maladaptive perfectionism as a possible intervening variable. Journal of Nervous and Mental Disease, 196, 144-152.

Stumpf, H., \& Parker, W. D. (2000). A hierarchical structural analysis of perfectionism and its relation to other personality characteristics. Personality and Individual Differences, 28, 837-852.

Wang, Q., Pomerantz, E. M., \& Chen, H. C. (2007). The role of parents' control in early adolescents' psychological functioning: A longitudinal investigation in the United States and China. Child Development, 78, 1592-1610.

Whiffen, V. E., \& Sasseville, T. M. (1991). Dependency, self-criticism and recollections of parenting: Sex differences and the role of depressive affect. Journal of Social and Clinical Psychology, 10, 121-133.

Wood, J. J. (2006). Parental intrusiveness and children's separation anxiety in a clinical sample. Child Psychiatry and Human Development, 37, 73-87.

Zuroff, D. C., Mongrain, M., \& Santor, D. C. (2004). Conceptualizing and measuring personality vulnerability to depression: Revisiting issues raised by Coyne and Whiffen (1995). Psychological Bulletin, 130, 489-511. 